\section{Healthcare organizations, linguistic communities, and the emblematic model of palliative care}

\author{
Organizações de saúde, comunidades lingüísticas e \\ o modelo emblemático dos cuidados paliativos
}

\footnotetext{
${ }^{1}$ Escola de Medicina e Cirurgia, Universidade Federal do Estado do Rio de Janeiro, Rio de Janeiro, Brasil. 2 Escola Nacional de Saúde Pública Sergio Arouca, Fundação Oswaldo Cruz, Rio de Janeiro, Brasil. 3 Departamento de Pós-graduação em Filosofia Universidade Gama Filho, Rio de Janeiro, Brasil.

Correspondence P. R. Vasconcellos-Silva Disciplina de Bioética, Escola de Medicina e Cirurgia, Universidade Federal do Estado do Rio de Janeiro. Rua Silva Ramos 321, Ramos, Rio de Janeiro, $R J$ 20270-330, Brasil. bioeticaunirio@yahoo.com.br prvasconcellos@uol.com.br
}

\begin{abstract}
The linguistic-communicative paradigm offers some interesting perspectives in a context where the perception of patient needs is considered a critical step in high-quality care. This study describes healthcare organizations as linguistic communities based on the conceptual framework of Habermas' communicative action theory. Four communicative models are present in healthcare settings: objectifying-instrumental (hegemonic model), where elements of interaction are objectified for clinical purposes; dialogic model with strategic perspectives, in which conversations are used unilaterally as tools to access subjective states; non-dialogic-transmissional model, in which linguistic exchanges are replaced with artifacts to transmit information; and full communicative model (present in palliative care based in homecare and informal caregivers, emphasizing health team/family interactions). Based on these premises, we considered palliative care an emblematic communicative model based on multidisciplinary teams devoted to transdisciplinary collaboration. In these settings, linguistic interaction with patients and their families could provide a solid basis for organization of healthcare networks.
\end{abstract}

Humanization of Assistance; Hospice Care; Linguistics; Communication
Paulo R. Vasconcellos-Silva 1

Francisco Javier Uribe Rivera 2

Flávio Beno Siebeneichler 3

\section{Introduction}

The latter half of the 20th century witnessed trends towards fragmentation of healthcare staff in spatial and cognitive domains. Professional organizations were based on the premise of technical competence and autonomy in their operating centers. Excessive professional autonomy proliferated in the absence of management direction, added to the shared vision of a system of independent clinics. Fragmentation ended up influencing the organizational formats and institutional culture 1 , whereby communicative processes became monologic and specialized, creating counterproductive distances. In contrast, in the last 30 years, palliative care and research in end-oflife care followed peculiar paths, involving three phases 2 - in the first two phases the focus was on the clinical dimension and organization level of services, respectively. In the last phase, still not mature, the focus is on quality end-of-life care as a regional health system issue 2 .

The introduction of measures to enhance coordination and cooperation of intra- and extramural care appears to be an improvement compared to standard community care. Terminal cancer patients are frequently readmitted to hospitals against their wishes. This is apparently due to poor communication among professional caregivers and/or overburdening of informal caregivers. Smeenk et al. 3 investigated the effects of a transmural homecare program intend- 
ed to optimize communication, cooperation, and coordination between intra- and extramural healthcare organizations (transmural care). When compared to the control group, which received the standard community care, transmural care patients underwent significantly less re-hospitalization during the terminal phase of their illness, while the intervention made a significantly positive contribution to the patients' "physical" quality of life. Studies on the economic implications of homecare service programs suggest that installing them in every hospital with a multidisciplinary oncology unit is recommended for cancer patients. In another study, Smeenk et al. 4 found significantly lower pharmaceutical and rehospitalization costs in the homecare group, and the program proved to have significantly positive effects on both the patient's and direct caregiver's quality of life.

In the Latin America context, we observed the same trends in the organization of palliative care services. In addition, according to Bruera et al. 5, Latin American physicians were significantly more likely to support beneficence and justice in their daily decision-making as compared to Canadian physicians. Chan 6 observed that the Western-liberal model of decision-making for the terminally ill contrasts with the communicative model found in some Latin American and Asian countries, where palliative care professional measures concentrate on close approaches like home visits, in which healthcare providers make contact with their patients' "affective environment". Under these circumstances, the diagnostic premises and urgency of anticipating prognoses are undone. During home visits, fertile ground is cultivated for interdisciplinary action. Healthcare teams move out of their customary "habitat" to observe patients integrated in their social/family environment. Individuals and their life histories are defined as they unfold before the healthcare professionals, in the daily struggle with the fears and anxieties that the imminence of finitude adds to their difficulties.

\section{Hospitals as linguistic communities: colonization of the lifeworld}

Organizations can be described through the metaphor of either a machine or a living organism 7; alternatively, they could also be analyzed through a communicative approach, as linguistic communities. From a communicative perspective, an organization can be characterized by the wealth of its interactions and commitments 8,9,10 structured on speech acts (utterances as acts expressed in various ways, such as requests for clarification, recommendations, or recriminations) 11,12 . Organizations comprise the milieu of understandings and assumptions shared within a culture that permeate everyday interactions 9 .

This conceptual model facilitates the analysis of mismatches between lay and healthcare team perspectives. There are communicative acts in the interaction between cultures and values present in various daily acts. At given moments such understanding is hindered by the multiplicity of cultural niches in the hospital settings. The latter acquire growing complexities due to two phenomena of a common nature: the increasing variety of items in the contemporary cultural scenario and the proliferation of subcultures in specialized hospital domains 13,14. Multiple worldviews, lay and professional, converge in this linguistically complex community. However, all the premises are developed against a common backdrop, that of the "lifeworld". The latter is a concept developed by Habermas 15 from the works of Husserl and Schutz and is admitted as a set of the pre-interpretations and implicit knowledge we refer to in conversations. For Habermas 15, the lifeworld refers to the symbolic space where meaning, solidarity, and personal identity are linguistically communicated. It is distinguished by reflexive discourse, human rights, and relationships and aims at consensus through reasoned dialogue 15 . According to Rivera 13 (p. 58), it is the "horizon on which a speech action is realized". It is structured through meaningful symbols, communicated through verbal action orientated toward understanding. Based on this transcendental structure, the contents emerging in discourses become contextualized in a given time and place. The lifeworld, therefore, is constructed and reproduced through verbal language and comprises culture, the social world, and personality 15. The technology of diagnosis and cure tends to validate itself through its own ends and means. This format of alienation excludes the richest and most critical windows for glimpsing horizons. It creates difficulties in the synthesis following the analysis of problems that proliferate in the lifeworld crossroads between technology and symbolic interaction.

Mishler 16,17, applying Habermas' theory to medical encounters, provides a useful way of examining doctor-patient communication. The author portrayed the dialectical struggle between the voice of medicine and the lifeworld, supporting the premise that increased use of the latter makes for better outcomes and more humane treatment of patients as unique human beings. This would require attention to structural aspects of the healthcare system to enable doctors to work fully within the patient-centered model. 
Barry et al. 18 showed that doctors appeared to switch their communication strategy depending on whether they perceived the patient to be presenting with physical or psychological problems. When they employed the "strictly medical discourse" (for acute physical problems), this appeared to be a successful strategy. As long as there were no hidden concerns, patients did not suffer from exclusion of the lifeworld, and outcomes of the consultation were good. When doctors adopted the voice of the lifeworld in the so-called "mutual lifeworld consultations", for patients with psychological problems, this also appeared to be a successful strategy, even when patients were also suffering from physical conditions. Poorest outcomes occurred where patients used the voice of the lifeworld but were ignored (lifeworld ignored) or blocked (lifeworld blocked) by doctors' use of the voice of medicine (chronic physical complaints).

The present study highlights the communicative gaps present in hospital-centered models of care that overlook the importance of symbolic exchanges, as shown in Barry et al. 18. We present communicative models based on the work of Rivera 13 concerning communication in health systems based on a linguistic perspective. The latter is an application of Jurgen Habermas' communicative action theory and Austin and Searle's speech acts theory 12 . The need is emphasized for a model that combines technical and transdisciplinary action schemes to promote interaction between expert and lay cultures. In our conceptual framework, alienation is revealed by the linguistic perspectives in the mismatch of technical cultures and situations of common action. This confrontation results in "the impoverishment or emptying of the lifeworld" as pointed out by Siebeneichler 19 (p. 152) and Fredriksen 20. In such contexts, transmural palliative care opens up for a recast based on the Habermas communicative action theory and for an accompanying revision of the effectiveness of the purely technological approach.

\section{Communicative models}

The current models have been proposed on the basis of communicative resources and premises employed by healthcare professionals to organize their actions. They are not proposed as "closed" models within the linguistic matrix - it would be impossible to fit the whole wealth of contacts among patients and providers within their limits. Such categories seek to portray theoretical frameworks that become more comprehensible through the concept of health settings as linguis- tic interaction. The latter is executed through "actions as speech" structured by cultures, codes, legitimate orders, and worldviews.

There are no specialties that are innately and irreversibly monologic, transmissional, or communicative. Our objective is not to stereotype forms of communication in professional specialties or categories. For example, a general practitioner in a family health program who makes an effort to promote health can effectively do so through the influence of an argumentative attitude, full of symbolic exchanges in his daily action. On the other hand, he may feel that he promotes health efficiently by prescribing formulas for techniques in hygiene and sanitation that may not work properly. He can connect to the patient's family environment in various ways, obtaining different effects, whether by integration/interaction/full education (adopting a critical practice, in essence) or by the transmission of technical imperatives (as criticized by Baillie et al. 21 and Freire 22).

\section{The instrumental-objectifying model}

Anamneses are defined as semi-structured questionnaires, necessary to typify symptoms in their link to the "history of the current illness". Past illnesses are characterized thematically, along with the patient's history of physiological development, unhealthy habits, and environmental conditions etc. ${ }^{23}$. As questionnaires, they can be used not only as instruments to obtain information on diseases, but also to describe housing conditions and key cultural habits. Thus, data on nutritional characteristics, as well as habits such as chewing tobacco, among many other examples, can be clinically valuable as long as they are linked to pathophysiological mechanisms. As objectifying surveys, they investigate information that corroborates evidence of active nosological processes. In this process of extracting clinical data from a life history, techniques are developed that aim to suppress "subjective noise" which is scarcely useful for instrumental reasoning at that moment. Another distinctive trait of objectifying resources is their easy adaptation to statistics, due to the fact that the latter focuses on tabulating classifiable and quantifiable elements.

Therefore, although a channel for conversation is established, the dialogue acquires the characteristics of an investigation, conducted by professionals who are more or less skillful at cultivating trust in their clients 23 . Although proper clinical investigative technique acknowledges the need for interaction, the latter is viewed as an external element, linked to the interviewer's personal skills. Based on the demands for case reso- 
lution, histories of development, illnesses, housing conditions, sanitation, and family illnesses are relevant priorities. Descriptions of symptoms should comprise a portrait that is intended as objective and logical for planning therapeutic tactics, although such descriptions may also require dialogic actions that are not admitted as essential.

Thus, this model's distinctive trait is the attempt to access clinical situations through various techniques. Information on symptoms and life histories may be strategically necessary, in light of the ideal of correcting and stabilizing illnesses, without any communicative goal. This confers an aspect of objectification, asymmetry, and a-criticality in this communicative model. Questions are asked and narrowly defined answers are expected within established clinical formats. The attempt is to characterize some objectifiable elements of illness, described as symptoms that must be dredged from a "swamp of information and misinformation" 23 (p. 26). Such interactions are typically limited to the objective dimensions of organic dysfunction.

While in a full communicative model the references for understanding and action are grasped on the objective, social, and subjective planes, in technical action such dimensions are omitted. Thus, recourse to language tends to be merely transmissive (from the patient to the doctor). It does not aim at mutual understanding, since it involves objectively targeted successes. Both the subjective and the social/environmental/cultural components of the illness appear as variables external to it, although they interfere in its development.

\section{Dialogic model with strategic perspectives}

It is impossible to polarize the hospital scenario between instrumental monologues and ideal dialogues without running the risk of slipping into oversimplified concepts. There are specificities that cannot be omitted from this type of study: the conversations directed to the patient's subjective states that exclude the bidirectional nature of the understanding. In these models, although dialogues predominate, there is a persistent tendency to instrumentalize the speech acts in order to disguise the clinical intentions underlying the investigation of the symbolic plane. There are strategically determined technical urgencies that aim at obtaining tactically valued effects.

The discourse is disassembled by tools that break it down into its symbolic elements. This model works on the level of interpretations rather than with objective elements. Family practitioners who take interest in their patients' environ- ment, the family, and living conditions refer to the objective - or the setting as they perceive it, as technical experts - while in the dialogic/strategic model, the interest is focused on how the patients themselves reinterpret this same setting. The sources from the lifeworld of just one participant in the conversation are investigated. Knowledge reserves consolidated as interpretative models, values, competencies, modes of perception, and identities become specifically interesting to an "expert in subjectivity". The latter operates in scenarios like that of institutional psychiatry (in contrast with psychology and psychoanalysis as full communicative models) in search of psychopathogical categories to medicate with drugs.

Such models involve conversations led by essentially asymmetrical interactions. Subjective contents are certainly retrieved, although the action remains in the instrumental terrain, despite the dialogic formats. They focus on expectations, desires, anxieties, and fears originating from all sorts of drives, but remain essentially a-critical. Although the healthcare professional relies (asymmetrically) on these channels for subjective interconnection, this relationship always remains in the same dimensions.

In short, although these conversations are dialogic, they are also instrumental and teleological, that is, they pursue ends as strategic objectives. The instrumentalized speech acts are appropriate for the objectification of subjectivities. Thus, an emotional state is translated into psychopathological schemata for purposes of therapeutic interventions. "Specialist dialogues" are institutionalized as rites of semi-interlocution, filled with asymmetrical investigation and discourse. Since they are based on weakly relational goals, they frequently lead to communicative voids. They can easily lead to conflicts, when individuals are frustrated in their attempts to affirm their cultural values. In the terrain of instrumental rationality that operates in subjective dimensions, the deconstruction of the "lifeworld" is necessary to give rise to the notion of a self-transformed-into-object. As the recipient of emotions and values, it is dispossessed of itself.

\section{The transmissional/monologic model}

We have observed that the fragmentation of activities in daily actions tends to jeopardize the improvement of planes for staff interaction. Healthcare professionals also develop inabilities in "active listening" to their patients, who resent the lack of situations with symmetrical dialogue. In this scenario full of monologues, how can the system's rationality transmit to patients what are considered essential contents for the treatment 
plan? How can one put a system in motion towards the ideals of cure without giving some information back to patients? In the preparation for complex, bloody, or invasive procedures, the search for information to clear up doubts and offset anxieties is predictable 24,25,26. Nevertheless, the effects of professional action transcend mere technical intervention. Under certain circumstances, professional action can shift or interrupt individual life projects and trajectories. Such demands are fully recognized on the personal level. However, on the institutional plane the need for effective interventions has posed new challenges for the specialists' skills in elaborating appropriate instruments. Fears and cognitive gaps derived from cultural identities, emotional states, and biological variables become mixed and confused. As discussed above, technical action on the transmissive level became specialized in extracting the necessary data through the investigational format. Within this linear focus, how does one refer back what are considered necessary contents? How does one develop techniques to transmit information that bridges the entire width and depth of adverse subjective states?

\section{- Communicative prostheses and technical biases}

From the transmissional perspective, the "translation" and dissemination of a portion of technical knowledge is confused with demands for dialogical interactions. The equation "comprehensibility $=$ transmission $=$ assimilation $=$ behavioral effect" has not proven effective in all the scenarios in which it was studied. VasconcellosSilva et al. 14,27 analyzed several experiences in the development of expertise in transmission of printed information by teams of specialists in healthcare settings. In their role of transmitting information, such leaflets prove extremely useful as accessories. Nevertheless, in some cases leaflets become "prostheses" when their authors admit the feasibility of replacing natural utterances with written texts. The latter frequently fail to relieve anxieties, although they may be useful for transmitting essential data sought by patients. Although the plan is to influence individuals, their utilization disregards interaction as a process of symbolic exchange between patients and healthcare teams.

Instrumental treatment of human communication presupposes some utopias, including the notion of univocal messages. They become invariant, independent of the culture and subjective states of those who "consume" them. In short, the target public's motivations and interests are idealized, regardless of the real particu- lar perspectives. Rozemberg et al. 28 highlights the paradox between the abundant production of such materials and the paucity of research on how they are received. The idealized perspective towards consumers of printed information adds difficulties for the accurate perception of their individual comprehension mechanisms.

Numerous studies have associated behavior changes with the mere transmission of specific information, denoting a cognitivist view of health education. The metaphor used by Freire 22 in this context is that the power needed to change behavior is "stored" in the organization as a bank. Several authors have investigated the efficacy of readability scores to evaluate information leaflets $29,30,31,32$. The cognitivist focus permeates the readability hypothesis as the key to their communicative efficacy. According to this framing, cognitive mismatches are responsible for the failure of these texts to modify behaviors.

Inter-subjective links are replaced by standardized prostheses that are believed to "normalize" patients' behavior. Kee 24 highlights physicians' paternalistic tendency in the selection of what they consider important information. In this study, healthcare professionals saw themselves as the best interpreters of therapeutic options, and thus responsible for the most important decisions. The effect of the unilateral nature of the messages that are supposed to be assimilated ends up frustrating the authors. This may be explained by the lack of systematic channels for listening, capable of expanding the room for discourse by the principal stakeholders.

As an exception that reinforces this last argument, Foltz \& Sullivan 33 evaluated cancer information leaflets produced by two American reference organizations (the National Cancer Institute and the American Cancer Society). The printed materials were considered complex, with non-uniform readability. In reception studies, patients emphasized the need to discuss aspects related to emotions and sex, issues frequently absent from printed materials. Meredith et al. 26 described other examples of unperceived demands by studying leaflets on prostate surgery. The authors observe that in addition to the inadequate terminology and lack of uniformity in the leaflets, there were frequent omissions concerning sexual function and the potential for malignant conversion of tumors. They highlight the relevant and partially unmet demand for information on these topics (sex and malignant conversion). In short, in the leaflets studied by the above authors, sex and disease/death were not priority themes.

Mazur \& Hickham 34 reached conclusions that reaffirm the need for symmetric discursive approaches in the hospital. The author contends 
that it is not the load (or amount) of information that intervenes in patients' decisions and options, ascribing behavior change to the level of data explanation (which could be achieved easily by natural conversations). Other studies agree that patients who feel that they are participating in their treatment decision options achieve greater treatment success rates (e.g., Schulman 35, in treatment of arterial hypertension). Based on a systematic review of dozens of controlled, randomized trials, Stewart $36 \mathrm{ob}$ served that more efficient communication with patients was significantly correlated with more favorable evolution.

Other strategies with more relational perspectives (counseling, talks, and debate groups) were also identified in our review, although as adjuvant approaches. Simpson et al. 37 acknowledges effective behavior in the positive attitudes of some midwives in influencing pregnant women to adhere to prenatal HIV testing. In general, studies that present more positive results show that they occur in the area of closer and more stable personal interactions. There were illustrative differences in the group of patients supported by counselors as compared to those who received printed materials. The above-mentioned study recommends training specialized staff to transmit information through discourse and highlights the positive effect of personal stances by these players vis-à-vis the problems at stake.

The transmissional perspective adds some difficulties by concentrating exclusively on cognitive gaps, shifting its view from the importance of the discursive recourse in symmetrical conditions. This tendentiousness may be attributable to the healthcare professional's self-image as the reservoir of scientific information to be transmitted vertically through a print media to a mute recipient (in the kind of "bank account education" model criticized by Freire 22).

\section{Full (non-transmissional)}

communicative model

Situations in which healthcare professionals and patients agree to coordinate their action plans according to mutual and symmetrical inter-subjective recognition are classified as the full communicative model. This definition is based on the Habermasian concept of communicative action. The latter can be described as a rational motivation for adherence based on the illocutionary effect - argumentative strength of a discourse - of commitment that a speech act elicits 15 . Under a communicative framing, Habermas foresaw the basic premise of a theory establishing the primacy of social interaction processes for society's evolution ${ }^{38}$. He pursued the description of a particular form of rationality in communicative processes (subject-subject relations) as opposed to cognitive and positivist framing (subject-object relations). Language, as a complete expression of our representations and thoughts, would allow access to the structure of rationalities manifested in any social system. Based on this premise, Habermas presents the imperative of mutual understanding as social paradigm, grounded on the coordination of actions between individual players using language as the basic condition for interaction.

Transposition of these premises to this field of study serves as the basis for proposing the evolution of health professionals' action based on the need for understanding and commitment between healthcare staff and their patients through linguistic exchanges. The paradigm of therapeutic pacts (and no longer strategies for professional intervention) as commitments to action would depend on the development of ideal conditions for inter-subjective exchanges. In light of the last studies discussed above, one can already admit the urgency of such skills in areas where the lack of dialogue leads to communicative prostheses.

\section{- Palliative medicine and new paradigms}

The concept of palliative care (as originally described by Kübler-Ross 39 and Saunders ${ }^{40}$ ) is permeated by ethical issues related to professional-patient-family interaction, concentrated on great proximity and oriented towards communication about quality of life at all levels. As the substantial premise, it shifted the focus from the sacredness of life of classical medicine, shedding light on the need for efforts towards the preservation of dignity, autonomy, and quality of life 2. Nonetheless, Caron et al. ${ }^{41}$, Meier et al. 42 , and Billings \& Block 43 highlighted the lack of material on this subject in classical medical textbooks, identifying deficiencies in medical training on contents and disciplines dealing with the borders of finitude. According to Ellis et al. 44 even among specialists (clinical oncologists) who face such scenarios daily, there are no harmonious concepts on this type of situation.

In many Western countries a deeper comprehension of the need to improve end-of-life care is gradually emerging. As argued by Singer 2, technological advances in medicine have obscured the need for human compassion for the dying. According to him, there is a growing public demand for a more comprehensive, interdisciplinary, and integrated approach toward health and illness. Published literature provides evidence that the quality of end-of-life care is often unsat- 
isfactory for both patients and families: Solomon et al. 45 reported $78 \%$ of healthcare professionals that sometimes felt the treatments they offered patients were overly burdensome, and Hanson et al. 46 described bereaved family members that felt that communication concerning end-of-life care issues was impersonal.

This type of activity makes several breaks with the instrumental paradigms that are still hegemonic in society. Palliative care is a field of action for professionals with various types of training, transcending the application of formalized techniques in the effort to care for patients in the advanced stages of chronic disease. In addition, palliative care teams help families of patients adapt to daily technical and emotional needs 47 . They thus focus on objective issues (analgesia, care for wounds, nutritional orientation) and other needs related to other individual dimensions (psychological, socio-familiar, spiritual). That could settle a field where coordination of actions is built on communicatively established consensus. In palliative care, actions are based on implicit agreement on patient-family interpretations, through recognizing the validity of the patient's verbal statements, subjected to ethical reflections. Consensus is ideally based on linguistic communication, which can always, in principle, be contested and made the object of later discursive tests.

Singer 48 contends that such progress is achieved as the result of advances in the exercise of clinical practice, at the organizational level, and in the health system as a whole. He particularly highlights the initiatives to reinforce continuing education programs for healthcare professionals, shifting the focus from training of specialists to the education of physicians in general concerning finitude.

In short, palliative care concentrates its attributes on the approach between the healthcare team, patients, and the family on levels that transcend the clinical dimension. This activity thematically approaches not only technical issues but also subjective states derived from "existential discomfort" in the face of finitude. The perspective of palliative care specialists is expanded on a level with the experience of the patients and their family members. This creates the conditions for healthcare professionals to shed the principles of sacredness of life and to approach the principles of quality of life. As pointed out by Singer 49 quality end-of-life care identified by expert clinicians may not be the same as that identified by patients themselves. Such contacts provide unique forms of learning, whereby patients and their families benefit from the experience allowed by the simultaneous perspectives of various professional categories. On the other hand, the professionals are exposed to a unique experience: moments of serene farewell that are rarely observed in intensive care units and emergency wards. Thus, they develop a view that transcends diagnostic and therapeutic projects. This experience offers them interesting conditions for overcoming the frustrations deriving from the limitations of instrumental reason in dealing with such issues. They all free themselves from the framings that see the hospital as the only adequate scenario to begin and end life. In dialogic contexts, opportunities are created to overcome ancestral fears: an "emancipatory function" stripped of technical objectives and closely aligned with the driving interest of communicative action.

\section{Conclusion}

In this study we have provided a portrait of healthcare organizations as transcendent linguistic communities. Within this context, the specialist-based activities pose one of the main obstacles to the fluency of dialogues and integration of healthcare teams in interdisciplinary projects. The phenomenon of knowledge diversification leads medicine to realize that its task will not be completed under the classical format, involving the sum of teams of isolated specialists in hospital grand rounds. In the monologic/ transmissional model, we observe traits of the technical bias that cultivates distances and communicative distortions. From the communicative perspective, these distortions are concentrated in the elimination of ordinary language as a mediating force. Specialists opt to reproduce in "communicative prostheses" their cognitive worldviews, in which the impoverishment of symbolic exchanges exempts them from the fluency of dialogues. In the dialogic/strategic communicative model, we observe the tactics of unilateral access to a subjective world, sometimes portrayed in reports of psychopathology. Therefore, the possibilities such structures offer for understanding are limited to the objective, social, and subjective dimensions contained in the technical rationalization limits.

On the other hand, the opposite effects have been observed in emerging activities that emphasize interactions for symbolic exchanges mediated by language. In this framework, palliative care poses a form of dynamically self-adjusted knowledge based on its insertion into the linguistic and cultural context in which the illness develops. In this sense, it promotes the interaction of patients with various professional groups in the search for consensus vis-à-vis rules to orient their discus- 
sions. In the imminence of death, such formats for interaction become an important reference.

In short, we believe that the ability of healthcare teams to communicate remains perennial, although underutilized. The sites for communicative action, like palliative care, should be stud- ied better as examples. One perceives in them the fluency of an idiom that allows them to recognize and ensure spaces for otherness. It would be useful and timely to understand the factors that have shifted them from the instrumentalist approaches to such promising paths.

\section{Resumo}

O paradigma lingüístico-comunicativo tem a oferecer perspectivas interessantes em um contexto no qual a percepção das necessidades dos pacientes é tida como um passo essencial à humanização da assistência. $O$ presente estudo descreve as organizações de saúde como comunidades lingüisticas com base no marco conceitual da teoria da ação comunicativa de Habermas. No contexto assistencial estão presentes quatro modelos comunicativos: objetivador-instrumental (modelo hegemônico), no qual elementos da interação são objetificados em vista de propósitos clínicos; dialógico com perspectivas estratégicas, no qual as conversações são utilizadas unilateralmente como ferramentas para obter acesso a estados subjetivos; adialógico-transmissional, no qual as trocas lingüísticas são substituídas por artefatos para transmissão de informações; comunicativo pleno, presente nos cuidados paliativos organizados ao redor da assistência domiciliar e dos cuidadores informais, enfatizando a interação entre equipes de saúde e familiares. Com base em tais premissas, consideramos os cuidados paliativos como modelos comunicativos emblemáticos porque fundamentados em times multidisciplinares dedicados à mútua colaboração transdisciplinar. Nesse cenário, a interação lingüística com pacientes e seus familiares serviria como base estruturante das equipes assistenciais.

Humanização da Assistência; Cuidados Paliativos; Lingüística; Comunicação

\section{Contributors}

P. R. Vasconcellos-Silva participated with the literature review, elaboration of concepts, and drafting of the final article. F. J. U. Rivera and F. B. Siebeneichler contributed to the analysis of concepts and review of the manuscript. 


\section{References}

1. Mintzberg H. Criando organizações eficazes: estruturas em cinco configurações. São Paulo: Editora Atlas; 1995.

2. Singer P. Quality end-of-life: a global perspective. BMC Palliat Care 2002; 1:4.

3. Smeenk FW, de Witte LP, van Haastregt JC, Schipper RM, Biezemans HP, Crebolder HF. Transmural care. A new approach in the care for terminal cancer patients: its effects on re-hospitalization and quality of life. Patient Educ Couns 1998; 35:189-99.

4. Smeenk FW, Ament AJ, van Haastregt JC, de Witte LP, Crebolder HF. Cost analysis of transmural home care for terminal cancer patients. Patient Educ Couns 1998; 35:201-11.

5. Bruera E, Neumann CM, Mazzocato C, Stiefel F, Sala R. Attitudes and beliefs of palliative care physicians regarding communication with terminally ill cancer patients. Palliat Med 2000; 14:287-98.

6. Chan HM. Sharing death and dying: advance directives, autonomy and the family. Bioethics 2004; 18:87-103.

7. Morgan G. Imagens da organização. São Paulo: Editora Atlas; 1996.

8. Flores F. Inventando la empresa del siglo XXI. Santiago de Chile: Hachette; 1993.

9. Flores F. Creando organizaciones para el futuro. Santiago de Chile: Dólmen Ediciones; 1994.

10. Zafirian P. Trabalho e comunicação nas indústrias automatizadas. Tempo Social 1991; 3:119-30.

11. Searle JR. A taxonomy of illocutionary acts in language, mind and knowledge. Minneapolis: University of Minnesota Press; 1976.

12. Austin JL. How to do things with words. Oxford: Oxford University Press; 1962.

13. Rivera FJU. Agir comunicativo e planejamento social: uma crítica ao enfoque estratégico. Rio de Janeiro: Editora Fiocruz; 1995.

14. Vasconcellos-Silva PR, Rivera FJU, Rozemberg B. Próteses de comunicação e alinhamento comportamental: uma revisão da literatura sobre impressos hospitalares. Rev Saúde Pública 2003; 37:53142.

15. Habermas J. The theory of communicative action. v. 1: reason and the rationalization of society. Boston: Beacon Press; 1984.

16. Mishler EG. Viewpoint: critical perspectives on the biomedical model. In: Mishler EG, Amarasingham LR, Hauser ST, Liem SD, Osherson R, Waxler NE, editors. Social contexts of health, illness and patient care. Cambridge: Cambridge University Press; 1981. p. 177-8.

17. Mishler EG. The discourse of medicine: the dialectics of medical interviews. Norwood: Ablex; 1984.

18. Barry CA, Stevenson FA, Britten N, Barber N, Bradley CP. Giving voice to the lifeworld. More humane, more effective medical care? A qualitative study of doctor-patient communication in general practice. Soc Sci Med 2001; 53:487-505.

19. Siebeneichler FB. Colonização do mundo vital. In: Siebeneichler FB, organizador. Jurgen Habermas: razão comunicativa e emancipação. Rio de Janeiro: Editora Tempo Brasileiro; 1989. p. 151-3.
20. Fredriksen S. Instrumental colonisation in modern medicine. Med Health Care Philos 2003; 6: 287-96.

21. Baillie L, Basset-Smith J, Broughton S. Using communicative action in the primary prevention of cancer. Health Educ Behav 2000; 27:442-53.

22. Freire P. Pedagogia do oprimido. Rio de Janeiro: Editora Paz e Terra; 1979.

23. Judge RD, Zuidema GD, Fitzgerald FT. Clinical diagnosis: a physiologic approach. Boston: Little, Brown and Company; 1982.

24. Kee F. Patients' prerogatives and perceptions of benefit. BMJ 1996; 312:958-60.

25. Fawdry R. Prescribing the leaflets. BMJ 1994; 51:551-3.

26. Meredith P, Emberton M, Wood C, Smith J. Comparison of patients' needs for information on prostate surgery with printed materials provided by surgeons. Qual Health Care 1995; 4:18-23.

27. Vasconcellos-Silva PR, Rivera FJU, Castiel LD. Comunicação instrumental, diretiva e afetiva em sistemas hospitalares. Cad Saúde Pública 2003; 19:1667-79.

28. Rozemberg B, Silva APP, Vasconcellos-Silva PR. Impressos hospitalares e a dinâmica de construção de seus sentidos: o ponto de vista dos profissionais de saúde. Cad Saúde Pública 2002; 18:1685-94.

29. Glanz K, Rudd J. Readability and content analysis of print cholesterol education materials. Patient Educ Couns 1990; 16:109-18.

30. Murphy B, Schofield H, Herman H. Information for family careers: does it help? Aust J Public Health 1995; 19:192-7.

31. Mumford ME. A descriptive study of the readability of patient information leaflets designed by nurses. J Adv Nurs 1997; 26:985-91.

32. Chung V, Horowitz AM, Canto MT, Siriphant P. Oral cancer educational materials for the general public: 1998. J Public Health Dent 2000; 60:49-52.

33. Foltz AT, Sullivan JM. Limited literacy revisited: implications for patient education. Cancer Pract 1999; 7:145-50.

34. Mazur D, Hickham D. The effect of physicians' explanations on patients' treatment preferences: five-year survival data. Med Decis Making 1994; 14:255-8.

35. Schulman BA. Active patient orientation and outcomes in hypertensive treatment: application of a socio-organizational perspective. Med Care 1979; 17:267-80

36. Stewart MA. Effective physician-patient communication and health outcomes: a review. Can Med Assoc J 1995; 152:1423-33.

37. Simpson WM, Johnstone FD, Boyd FM, Goldberg DJ, Hart GJ, Gormley SM, et al. A randomised controlled trial of different approaches to universal antenatal HIV testing: uptake and acceptability and Annex: antenatal HIV testing - assessment of a routine voluntary approach. Health Technol Assess 1999; 3:1-112.

38. Habermas J. Knowledge and human interests. Boston: Beacon Press; 1972.

39. Kübler-Ross E. Sobre a morte e o morrer. São Paulo: Editora Martins Fontes; 1981. 
40. Saunders C. Hospice and palliative care: an interdisciplinary approach. London: Edward Arnold; 1991.

41. Caron AT, Lynn J, Keaney P. End-of-life care in medical textbooks. Ann Intern Med 1999; 130:826.

42. Meier DE, Morrison RS, Cassel CK. Improving palliative care. Ann Intern Med 1997; 127:3-5.

43. Billings JA, Block S. Palliative care in undergraduate medical education: status report and future direction. JAMA 1997; 278:733-8.

44. Ellis MR, Vison DC, Ewigman B. Addressing spiritual concerns of patients. J Fam Pract 1999; 48:105-9.
45. Solomon MZ, O'Donnell L, Jennings B, Guilfoy V, Wolf SM, Nolan K, et al. Decisions near the endof-life: professional views on life-sustaining treatments. Am J Public Health 1993; 83:14-23.

46. Hanson LC, Danis M, Garrett J. What is wrong with end-of-life care? Opinions of bereaved family members. J Am Geriatr Soc 1997; 45:1339-44.

47. Billings JA, Block S. Recent advances: palliative care. BMJ 2000; 321:555-8.

48. Singer PA. Medical ethics: recent advances. BM] 2000; 321:282-5.

49. Singer PA, Martin DK, Kelner M. Quality end-of-life care: patients' perspectives. JAMA 1999; 281:163-8.

Submitted on 22/Nov/2005

Approved on 18/Jan/2007 